\title{
A crise fiscal dos estados e o Regime de Recuperação Fiscal: o déjà vu federativo
}

\author{
Raphael Guilherme Araujo Torrezan 1 \\ Cláudio César de Paiva ${ }^{1}$ \\ 1 Universidade Estadual Paulista / Faculdade de Ciências e Letras de Araraquara, Araraquara / SP - Brasil
}

Discussão acerca da crise fiscal dos estados e do Regime de Recuperação Fiscal (RRF), promulgado no ano de 2017, cujas medidas de ajuste são apontadas como fundamentais para o equilíbrio das contas públicas estaduais e que representam, no entanto, sob a perspectiva federativa, um enfraquecimento dos estados brasileiros, já que tais medidas afetam a autonomia político-administrativa destes entes subnacionais. O estado do Rio de Janeiro foi objeto desta pesquisa entre os anos de 2008 e 2019, pois foi o único a aderir ao RRF desde sua promulgação. $\mathrm{O}$ estudo indica que as medidas de austeridade adotadas pelo estado do Rio de Janeiro não foram suficientes para garantir a estabilidade financeira e o reequilíbrio das contas públicas. Dentre os resultados, destacam-se a manutenção da insolvência financeira, bem como o crescimento do endividamento do período, sendo o único resultado positivo, no âmbito dos termos do RRF, a redução dos gastos com pessoal. Por fim, observa-se que, até o penúltimo quadrimestre de 2019, o estado do Rio de Janeiro não cumpriu integralmente o acordo firmado com a União.

Palavras-chave: crise dos estados; federalismo fiscal; Regime de Recuperação Fiscal.

\section{La crisis fiscal de los estados brasileños y el Régimen de Recuperación Fiscal: el déjà vu federativo}

Este artículo tiene como objetivo discutir la crisis fiscal de los estados brasileños y el Régimen de Recuperación Fiscal (RRF) promulgado en 2017, cuyas medidas de ajuste se consideran fundamentales para el saldo de las cuentas públicas estatales, pero también representan, bajo la perspectiva federativa, un debilitamiento de los estados brasileños, ya que tales medidas afectan la autonomía política y administrativa de estas entidades subnacionales. El estado de Río de Janeiro fue objeto de esta investigación entre los años 2008 y 2019 porque fue el único estado que se adhirió al RRF desde su promulgación. El estudio indica que las medidas de austeridad adoptadas por el estado de Río de Janeiro no fueron suficientes para garantizar la estabilidad financiera y el reequilibrio de las cuentas públicas. Entre los resultados, destacamos el mantenimiento de la insolvencia financiera, así como el crecimiento del endeudamiento en el período y el único resultado positivo dentro de los términos del RRF es la reducción de los gastos de personal. Finalmente, se observa que hasta el penúltimo cuatrimestre de 2019, el estado de Río de Janeiro no cumplió plenamente el acuerdo firmado con el Gobierno Federal.

Palabras clave: crisis de los estados; federalismo fiscal; Régimen de Recuperación Fiscal.

\section{The fiscal crisis of states and the Fiscal Recovery Regime: the federative Déjà Vu}

This article aims to discuss the fiscal crisis of the Brazilian states and the Fiscal Recovery Regime (FRR) enacted in 2017, whose adjustment measures are considered fundamental for the balance of state public accounts. Under the federative perspective, these adjustments represent a weakening of the states since such measures affect their political and administrative autonomy. The state of Rio de Janeiro was chosen as the subject of this research because it was the only state to join the FRR since its enactment, and the study used data from the years 2008 to 2019. The findings suggest that the austerity measures adopted by the state of Rio de Janeiro were not enough to guarantee financial stability and the rebalancing of public accounts. Among the results, we highlight that the state remained financially insolvent and the indebtedness for the period grew. The only positive result within the terms of the FRR was the reduction in the state's personnel expenses. Finally, it is noted that until the penultimate quarter of 2019, the state of Rio de Janeiro did not comply with the terms of the agreement signed with the federal government.

Keywords: crisis of states; fiscal federalism; Fiscal Recovery Regime. 


\section{INTRODUÇÃO}

No sistema federativo brasileiro, os governadores sempre exerceram, com exceção de breves períodos, grande influência na política e nos rumos da nação, o que possibilitou a perpetuação no poder de oligarquias estaduais. Não sem razão chegaram a ser denominados de "Barões da Federação" (Abrúcio, 1988).

Os áureos tempos de supremacia dos estados no pacto federativo começaram a se exaurir no início dos anos de 1990 com o esgotamento da capacidade da União de equacionar diferentes interesses estaduais por intermédio de mecanismos fiscais (fundos públicos), combinado com o processo de recentralização nas relações fiscais entre a União e as unidades subnacionais. A crise financeira dos estados precipitou um movimento de contínuo tensionamento nos pactos no âmbito dos arranjos institucionais que regulavam as relações entre os diferentes níveis de governo, impondo, consequentemente, mudanças nas relações de poder entre os entes federados. A coordenação federativa difusa, desde então, explica a instabilidade presente nas relações intergovernamentais, potencializando movimentos aparentemente contraditórios entre os entes federativos, o que tem promovido a ascensão de uma espécie de "federalismo sem pactuação".

Neste contexto de crise federativa, baixo crescimento econômico e de conjuntura de frustração de receitas, os estados passam novamente por uma situação fiscal-financeira crítica que reverbera na incapacidade de fazerem frente às suas obrigações, particularmente referentes a pagamento de dívidas com fornecedores, a folha de pagamentos e consequentes impactos sobre servidores ativos e inativos.

Com a promulgação da Lei Complementar (LC) n. ${ }^{\circ}$ 159/2017, que instituiu o Regime de Recuperação Fiscal (RRF) dos estados e do Distrito Federal, vislumbrou-se a recuperação da solvência dos estados brasileiros frente aos desequilíbrios das contas públicas e do elevado endividamento.

O presente trabalho tem o propósito de discutir e suscitar algumas considerações sobre as implicações da crise fiscal dos estados e do RRF, cujas medidas de ajuste são apontadas como fundamentais para o equilíbrio das contas públicas, mas que representam, também, sob a perspectiva federativa, um enfraquecimento dos estados brasileiros, já que tais medidas afetam a autonomia político-administrativa. $\mathrm{O}$ estado do Rio de Janeiro, por ter sido o único habilitado para adesão ao RRF, será objeto de análise e reflexões mais acuradas.

Para alcançar os objetivos traçados, o artigo está organizado em quatro seções, além da introdução e da conclusão. Na primeira seção, discutem-se o processo de descentralização e os desafios da disciplina fiscal dos governos subnacionais. Na seção seguinte, o propósito é realizar algumas considerações sobre o processo de deterioração recente das finanças dos estados brasileiros. Na terceira seção, apresenta-se um panorama do RRF, proposto para reequilibrar as contas dos estados que apresentam um quadro de insolvência fiscal e alto endividamento. Na quarta seção, são avaliados os impactos da implementação do RRF no estado fluminense, com o propósito de verificar se as medidas acordadas têm sido suficientes para reconduzir as finanças do estado ao reequilíbrio fiscal, ou seja, a um resultado primário capaz de estabilizar a dívida líquida. 


\section{DESCENTRALIZAÇÃO, DESEQUILÍBRIOS VERTICAIS E O DESAFIO DA DISCIPLINA FISCAL DOS GOVERNOS SUBNACIONAIS}

A progressiva deterioração das finanças estaduais e seus efeitos adversos na macroeconomia têm reforçado as críticas aos processos de descentralização fiscal e política que foram disseminados com as reformas econômicas e políticas do início da década de 1980 em diversos países ao redor do mundo.

Nas décadas de 1980 e 1990, sob auspiciosas bandeiras que apontavam a descentralização como uma forma de robustecer a democracia, promover maior eficiência alocativa, fortalecer os mecanismos de accountability e, portanto, romper com as principais patologias institucionais encontradas nas estruturas centralizadas, foi sendo forjado um consenso em torno da descentralização como um princípio ordenador das reformas estruturais, que modernizaria o setor público (Cheema \& Rondinelli, 1983; Faguet, 1997; 2004; Ligthart \& van Oudheusden, 2015; Melo, 1996; Paiva, Torrezan \& Paiva, 2016). A premissa de que a descentralização de responsabilidades pelos gastos públicos poderia gerar ganhos substanciais na eficiência alocativa de bens e serviços, dada a sensibilidade das autoridades locais em relação à heterogeneidade das preferências da população local (Musgrave, 1960 Oates, 1972; Tiebout, 1956), não tem sido empiricamente comprovada vis-à-vis a ineficiência ainda presente na provisão de bens e serviços públicos.

Em geral, os fatores responsáveis pela frustração das expectativas são atribuídos: a) aos diferentes níveis de esforço de execução da competência tributária; b) a diferentes níveis de efetividade dos gastos públicos; c) a diversidades socioeconômicas locais e regionais; d) à sobreposição entre as responsabilidades dos diferentes níveis de governo; e) à ineficiência dos mecanismos de transferências intergovernamentais; $\mathrm{f}$ ) à maior rigidez dos governos subnacionais no ajuste das despesas diante de choques adversos nas receitas. Logo, o princípio de que os gestores públicos são maximizadores benevolentes do bem-estar social não tem encontrado abrigo na realidade de muitos países.

$\mathrm{O}$ rápido crescimento da autonomia financeira e das responsabilidades na provisão de bens e serviços públicos pelos governos subnacionais, no âmbito das reformas e prescrições normativas do Federalismo Fiscal de "Primeira Geração"1 bem como a prevalência de restrições orçamentárias fracas (soft budget constraints) não permitiram que se avançasse nas reformas necessárias à implementação de princípios de boa governança financeira na administração pública, particularmente dos mecanismos institucionais indutores da disciplina fiscal aos entes subnacionais.

Os precários arranjos institucionais que regulam as relações federativas entre os diferentes níveis de governo em diversos países, agravados pela dificuldade de impor regras fiscais rígidas para controlar empréstimos e endividamento dos entes subnacionais, pactuadas constitucionalmente ou em legislação infraconstitucional, contribuíram para estimular a ingerência sobre orçamentos locais. Não ao acaso, a falta de uma regulação fiscal prudencial rígida tem resultado, recorrentemente, em irresponsáveis déficits fiscais crônicos e na instabilidade macroeconômica (Ahmad, Albino-War \& Singh, 2006).

A ausência de restrições orçamentárias rígidas (hard budget constraints), em um contexto de descentralização fiscal, permite que as operações fiscais dos governos subnacionais sejam invariavelmente contaminadas pelo problema do moral hazard (risco moral), isto é, os governos

\footnotetext{
${ }^{1}$ Para o Federalismo Fiscal de "Primeira Geração", a descentralização das funções do Estado em um arranjo federativo dividido em vários níveis de governo e pautado na transferência de competências fiscais do ente central para os governos subnacionais, acarretaria um aumento do bem-estar social e melhorias na oferta de bens e serviços públicos.
} 
subnacionais passam a assumir riscos orçamentários excessivos, sob a expectativa de que são too small to fail (Luc \& Badia, 2013), e que, portanto, o governo central garantirá o socorro financeiro (bailouts).

Destarte, a preocupação com a disciplina fiscal dos governos subnacionais já estava presente no século XVIII. O que pode ser observado na obra conhecida como The Federalist Papers, de Alexander Hamilton (1767), primeiro Secretário de Tesouro dos Estados Unidos. Desde então, têm sido ambíguas as interpretações sobre comportamentos fiscalmente irresponsáveis dos governos subnacionais. Se o "fiscal appeasement" tem sido utilizado para acomodar politicamente resultados negativos de políticas fiscais discricionárias promovidas pelos governos subnacionais, também é fato que esses gestores têm exercido de forma inadequada a autonomia financeira conferida pelo sistema federativo e adotam esses procedimentos motivados pela forte expectativa de resgate financeiro em situações de déficits fiscais crônicos ou pelo default de endividamento público do sistema.

Na verdade, quando os governos subnacionais deixam de observar a responsabilidade na gestão das finanças públicas, revelam uma contradição do processo de descentralização, uma vez que a eficiência e a maximização do bem-estar social, princípios fundamentais do Federalismo Fiscal de Primeira Geração, passam a estar seriamente comprometidas.

A harmonização das finanças de governos multiníveis sempre foi um grande desafio para o federalismo fiscal, já que as evidências sugerem que os gestores públicos locais não apresentam propriamente condutas responsáveis direcionadas à estabilidade orçamentária. Desconsideram, assim, um possível espraiamento de uma crise macroeconômica por toda a Federação em decorrência da irresponsabilidade fiscal dos entes subnacionais (Rodden, Eskeland \& Litvack, 2003)

Em um quadro de restrições orçamentárias fracas, com expectativas de resgate financeiro dos entes subnacionais, Luc e Badia (2013) apontam que: “[...] if subnational governments expect bailouts, their response to positive and negative revenue changes should be asymmetric. In case of negative revenue change, spending is not adjusted downward (or is adjusted less than in the case of no-bailout expectation)" (Luc \& Badia, 2013, p. 30).

Esse comportamento oportunista significa, em última instância, a negação da boa governança $e$ da responsabilidade do gestor público, particularmente no que se refere aos princípios do equilíbrio orçamentário e da accountability. Além disso, revela-se contraproducente em relação a um dos pilares fundamentais do processo de descentralização apontado pelo Federalismo Fiscal de Primeira Geração, uma vez que desequilíbrios orçamentários crônicos e níveis insustentáveis de endividamento tendem, em geral, a afetar a eficiência alocativa na provisão de bens e serviços públicos, reduzir potencialmente o nível de bem-estar e se transformar em instabilidade macroeconômica do governo central (Prud'Homme,1995).

A literatura especializada tem apontado a existência de importantes conflitos federativos em decorrência da falta de harmonização entre o esforço de estabilização macroeconômica, desenvolvido pelo governo central, e o financiamento das ações dos governos subnacionais. A par disso, têm sido difundidas prescrições normativas que procuram demarcar uma rígida disciplina fiscal no desenho federativo em sistemas com múltiplos níveis de governo, com o objetivo de garantir a responsabilidade na gestão orçamentária e a sustentabilidade intertemporal da dívida pública (Abrúcio, 2007; Caldeira, Wilbert, Moreira \& Serrano, 2016).

A insolvência dos governos subnacionais tornou-se uma preocupação fundamental em economias descentralizadas. Não é por outra razão que Ter-Minassian e Craig (1997), Ter-Minassian (1999), Shah (2000) sistematizaram alguns pontos que poderiam garantir maior harmonização e coordenação entre 
entes federativos em sistemas descentralizados. Segundo os autores, para conciliar essa problemática federativa são necessários: “a) clareza na definição da destinação das receitas e responsabilização dos gastos governamentais; b) mecanismos de transferências com regras claras, estáveis e transparentes; c) incentivo ao esforço fiscal; d) fixação de regras limitadoras do endividamento dos governos central e subnacionais" (Ter-Minassian, 1999, pp. 56-59).

Contudo, a existência de regras para empréstimos e endividamento ex-ante, particularmente em um ambiente institucional com restrições orçamentárias fracas, não constitui condição suficiente para garantir a responsabilidade fiscal e a solidez das finanças públicas dos governos subnacionais. É necessária também a construção de mecanismos direcionados para situações de insolvência dos entes subnacionais ex-post, tornando transparente as consequências e os custos financeiros e sociais dos ajustes fiscais nos quais deve incorrer o ente subnacional (Ter-Minassian, 1997).

Não há como deixar de reconhecer as características intrínsecas aos sistemas federativos. A heterogeneidade dos governos subnacionais quanto a tamanho, nível de desenvolvimento socioeconômico, estrutura de produção, efetividade da competência tributária é um dos elementos que devem ser considerados em sua avaliação (Abrúcio, 2005; Mora, 2016).

Nessa perspectiva, é oportuno observar que nem todos os desequilíbrios fiscais dos entes subnacionais referem-se a condutas de leniência fiscal ou oportunistas (opportunistic behaviour) dos governos subnacionais. A despeito de os países descentralizados serem intrinsecamente suscetíveis a gastos excessivos em situações de restrições fracas, o que se nota nestes países é que os desequilíbrios fiscais refletem, muitas vezes, os descompassos entre a descentralização de receitas fiscais e as responsabilidades pela execução das funções públicas pelos governos subnacionais, e, por consequência, a ineficiência dos mecanismos de transferências intergovernamentais para corrigir desequilíbrios vertical e horizontal.

A coordenação federativa difusa desse processo explica a instabilidade presente nas relações intergovernamentais em sistemas descentralizados, potencializando movimentos aparentemente contraditórios entre os entes federativos. Na verdade, trata-se de um movimento de contínuo tensionamento das relações pactuadas no âmbito dos arranjos institucionais que regulam as relações entre os diferentes níveis de governo.

Nas próximas seções, à luz dos aspectos teóricos aqui tratados, serão discutidos aspectos dos ajustes fiscais propostos aos governos estaduais, no âmbito da renegociação da dívida dos estados.

\section{DETERIORAÇÃO FISCAL RECENTE DOS ESTADOS BRASILEIROS E OS AJUSTES FISCAIS}

O debate sobre a deterioração das finanças dos estados retornou à pauta das renegociações federativas no biênio 2015-2016. Equivocadamente, o elemento basilar para essa discussão estaria na ingerência fiscal e financeira, que culminou na deterioração das finanças públicas subnacionais e no crescente acúmulo de passivos. O forte desaquecimento econômico entre os anos de 2014 e 2017 teria sido o estopim para a manifestação destes problemas.

O equívoco suscitado diz respeito ao fato de que as causas e as consequências deveriam ser compreendidas na perspectiva federativa e as soluções pactuadas nas bases de um federalismo cooperativo, não apenas perscrutadas sob o rigor do ajuste orçamentário e contábil.

A crise federativa evidencia-se com contundência na análise da atual crise fiscal-financeira dos entes subnacionais. A análise de alguns indicadores fiscais permite a sistematização dos estados 
endividados em dois grupos, conforme o Gráfico 1. Um primeiro grupo é composto pelos estados de São Paulo, Rio de Janeiro, Minas Gerais e Rio Grande do Sul, cujas características são: (i) endividamento superior, ou muito próximo, a 200\% da Receita Corrente Líquida (RCL); (ii) déficit primário, ou superávit inexpressivo. O segundo grupo, composto pelos estados do Amapá, Piauí, Santa Catarina, Bahia, Paraná, Mato Grosso do Sul, Distrito Federal e Rio Grande do Norte, apresenta uma situação fiscal menos precária em relação ao primeiro grupo, sobretudo por estar abaixo dos limites prudenciais de endividamento público estipulado pela Lei Complementar n 101/2000 - Lei de Responsabilidade Fiscal (LRF). Entretanto, demonstrou dificuldades na geração de superávit primário em cumprimento às obrigações correntes.

\section{GRÁFICO 1 DÉFICIT PRIMÁRIO EM \% DA RECEITA LÍQUIDA E DÍVIDA CONSOLIDADA LÍQUIDA EM \% DA RCL - 2016}

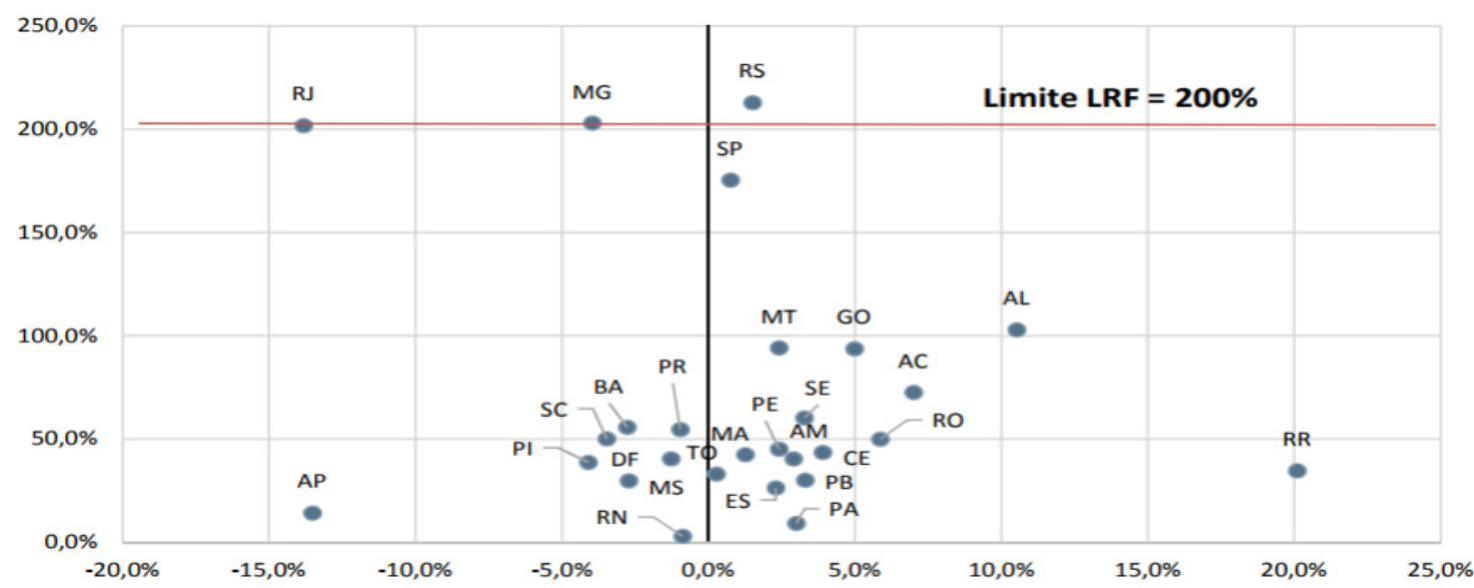

Fonte: Instituto Fiscal Independente (2017).

Dentre as causas responsáveis pela deterioração das finanças estaduais, encontra-se a situação errática das receitas públicas, tanto das receitas próprias quanto das oriundas de transferências da União. No período entre 2015 e 2016, houve redução de 9,5\% de receitas próprias em decorrência da crise econômica e de $2 \%$ das transferências oriundas da União. Além disso, no biênio 2015-2016 ocorreu a diminuição da arrecadação tributária de 17 estados da federação; dentre estes, Rio de Janeiro, Rio Grande do Norte e Espírito Santo apresentaram um arrefecimento na arrecadação superior a 10\%. Os quatro estados do Grupo 1 (São Paulo, Rio de Janeiro, Minas Gerais e Rio Grande do Sul), que concentram o maior estoque de dívida, apresentaram resultados negativos na arrecadação tributária, o que comprometeu significativamente a estabilidade das finanças dessas unidades federativas (Gráfico 2). 


\section{GRÁFICO 2 VARIAÇÃO PERCENTUAL DA RECEITA TRIBUTÁRIA E TRANSFERÊNCIAS POR ESTADO BRASILEIRO ENTRE OS ANOS DE 2015 E 2016}

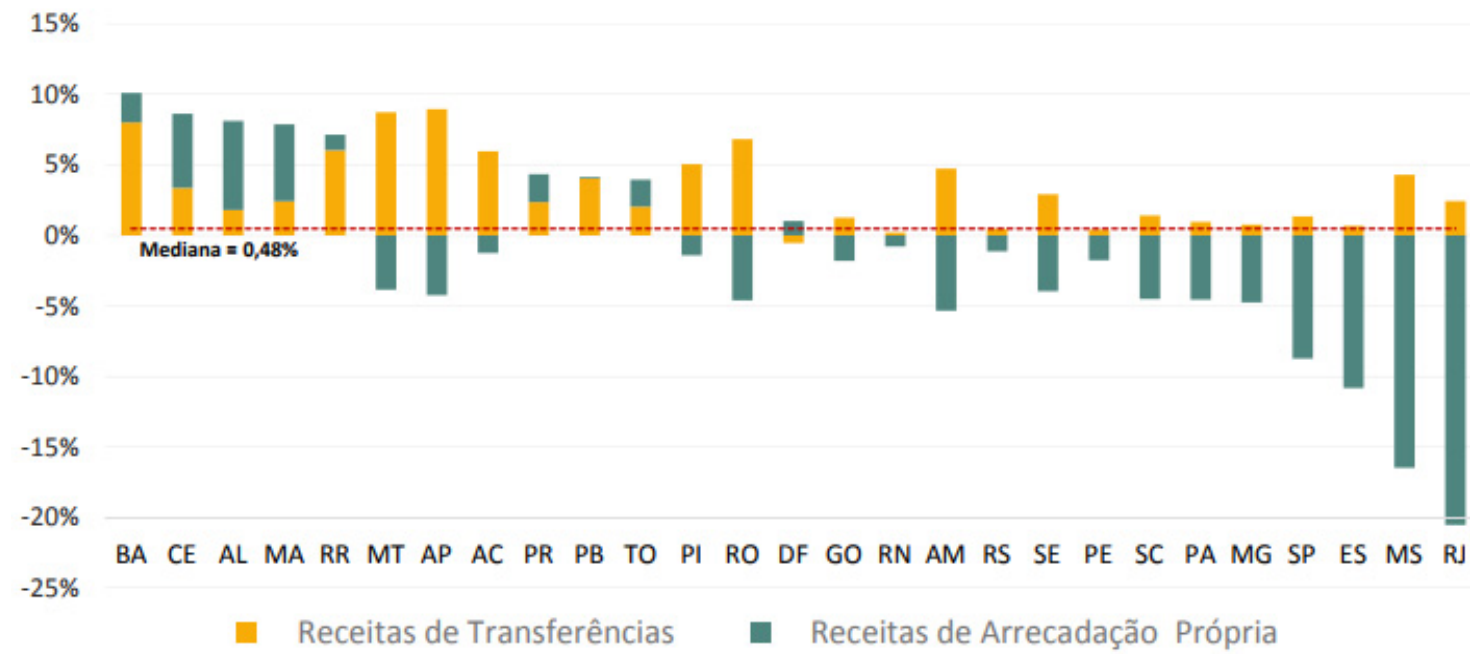

Fonte: Secretária do Tesouro Nacional (2017a, p. 19).

A escassez de recursos orçamentários em todos os estados da federação resultou em atrasos no pagamento de fornecedores, redução drástica dos investimentos e em dificuldades para a provisão de bens e serviços públicos pelos governos subnacionais. Um dos indicadores que mostram a insuficiência financeira para honrar compromissos assumidos é o volume de restos a pagar processados ${ }^{2}$, cuja existência indica um endividamento de curto prazo. De acordo com os dados, houve um aumento de $59 \%$ entre 2008 e 2016 dos restos a pagar processados dos estados, ou seja, as despesas acumuladas tiveram seu pagamento postergado para o ano subsequente, indicando a ausência de disponibilidade de recursos financeiros (Aquino \& Azevedo, 2017).

Os desarranjos nas contas públicas dos estados brasileiros adquiriram contornos ainda mais dramáticos em 2016 com a deterioração do resultado primário agregado. Em 2015, os orçamentos dos estados apresentaram conjuntamente um resultado primário superavitário de R 886 milhões, enquanto o resultado fiscal em 2016 apresentou um déficit primário de R 2,02 bilhões. De acordo com o Boletim de Finanças dos Entes Subnacionais (Secretaria do Tesouro Nacional, 2017a), essa variação decorreu do aumento de despesas com custeio. Este resultado fiscal-financeiro teria sido ainda mais grave se não tivesse sido atenuado com os recursos incorporados ao orçamento em decorrência da repatriação de ativos de $2016^{3}$.

Diante de um quadro de estrangulamentos fiscais-financeiros e de tensões no pacto federativo, os estados passaram a buscar alternativas para a superação dos problemas fiscais. A medida mais drástica foi adotada pelo estado de Santa Catarina, que pleiteou na Suprema Corte (Mandado de Segurança n. ${ }^{\circ} 34.023 / \mathrm{SC}$ ) a cobrança de juros simples sobre a dívida dos estados que foram refinanciadas em

\footnotetext{
${ }^{2}$ Despesas empenhadas e liquidadas, mas que não foram pagas até o dia 31 de dezembro.

${ }^{3}$ Regime instituído pela Lei Federal no 13.254/2016 para a declaração voluntária de recursos, bens ou direitos não declarados de origem lícita mantidos no exterior, que incorreu em um incremento arrecadatório de R\$ 50,9 bilhões aos cofres públicos no ano de 2016.
} 
1997. Em 28 de abril de 2016, iniciou-se o julgamento da dívida dos estados pelo Supremo Tribunal Federal (STF), momento que deve ser considerado um marco no sistema federativo brasileiro, pois a judicialização da discussão revelou a falência dos instrumentos tradicionais de negociação entre as diversas esferas federativas.

Em resposta à crise fiscal, foi editada a Lei Complementar n. ${ }^{\circ} 156$, de 2016, que permitiu o alongamento dos prazos dos estados por mais 240 meses, além de refinanciar as dívidas que envolviam recursos do Fundo de Garantia de Tempo de Serviço (FGTS) e do Banco Nacional de Desenvolvimento Econômico e Social (BNDES). O efeito de curto prazo dessa medida para os estados foi uma economia de aproximadamente $\mathrm{R} \$ 18,89$ bilhões (Secretaria Do Tesouro Nacional, 2017a) no serviço da dívida.

Essa nova legislação tinha um caráter de transitoriedade na contenção das despesas públicas, uma

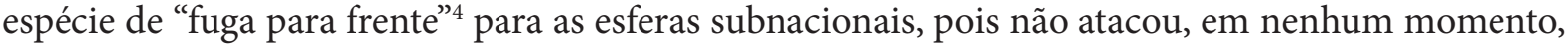
os alicerces estruturais dos problemas fiscais existentes, nem tampouco tratou da necessidade de um novo pacto federativo. A análise da evolução do estoque da dívida dos estados entre 2008 e 2017 mostra um crescimento real de $12 \%$ no período, o que não foi acompanhado pelo crescimento das receitas orçamentárias.

\section{UMA NOVA RENEGOCIAÇÃO COM OS ESTADOS - 0 REGIME DE RECUPERAÇÃO FISCAL}

O estrangulamento fiscal dos estados brasileiros levou a uma nova mobilização para encarar os desafios existentes. Sob diferentes vias, um aparente consenso formou-se em torno da solução desse conflito federativo, ainda que a saída imposta pela União em nada se alinhe aos preceitos federativos de cooperação, definidos pela carta constitucional. De um lado, encontravam-se as unidades federativas combalidas financeiramente e com sua estrutura financeira comprometida em decorrência de suas dívidas e da escassez de recursos. De outro, a União com a preocupação voltada exclusivamente para as consequências do descompasso fiscal-financeiro subnacional, uma vez que esse desequilíbrio poderia comprometer a estabilidade macroeconômica e gerar fortes crises econômicas, como ressaltam os estudos de Ter-Minassian e Craig (1997), Ter-Minassian (1999) e Shah (2000).

Neste contexto, o RRF foi instituído por meio da LC n. 159 (2017) e regulamentado pelo Decreto Federal no 9.109, de 27/07/2017, visando fornecer aos estados com graves desequilíbrios financeiros os instrumentos para o ajuste de suas contas mediante implementação de medidas emergenciais e de reformas institucionais determinadas em um Plano de Recuperação Fiscal, elaborado previamente pelo próprio ente federativo.

Na mensagem que acompanhou o Projeto de Lei Complementar (PLP) 343/2017, o qual originou a LC n. 159/2017, o governo federal esclarece que o reequacionamento de passivos é condição indispensável, porém não suficiente para eliminar a crise fiscal estrutural dos estados:

5. A reestruturação de débitos não solucionará a crise fiscal se não for acompanhada por esforço do estado que vise reequilibrar suas contas por meio de medidas estruturais e de medidas emergenciais. Por isso, a obtenção das prerrogativas acima elencados fica condicionada ao comprometimento do estado com um programa de ajuste de suas contas, por meio da aprovação de lei estadual contendo um Plano de Recuperação.

\footnotetext{
${ }^{4}$ Trata-se de expressão de origem francesa que se refere a recusa em encarar um problema sob a desculpa de que métodos arrojados estão sendo utilizados para solucioná-lo.
} 
É relevante notar que a LC n. 159 (2017), em seu artigo $3^{\circ}$, estabelece que um estado encontrase em condição fiscal-financeira grave quando apresentar cumulativamente três características: (i) receita corrente líquida (RCL) anual menor que a dívida consolidada ao final do exercício financeiro anterior ao pedido de adesão ao RRF; (ii) comprometimento com despesas com pessoal e serviço da dívida superior a 70\% da RCL do exercício; (iii) acúmulo de um volume total de obrigações contraídas superior a disponibilidades de caixa e equivalentes de caixa de recursos sem vinculação.

No momento em que o estado atender aos critérios de elegibilidade para adesão ao RRF, compromete-se a adotar uma série de medidas de austeridade, com o objetivo de garantir o reequilíbrio fiscal. O Quadro 1 sintetiza as obrigações e vedações instituídas pela LC n. 159 (2017) para resolver o problema da insolvência fiscal e alto endividamento dos estados.

\section{QUADRO 1 CONTRAPARTIDAS DOS ESTADOS PARA ADESÃO AO RRF}

\begin{tabular}{|c|c|}
\hline Obrigações & Ações que são vedadas ao ente subnacional \\
\hline $\begin{array}{l}\text { - Privatização de Empresas Públicas. } \\
\text { - Alterações no Regime Próprio de Previdência. } \\
\text { - Leilões para descontos de Restos a Pagar. } \\
\text { - Adoção de teto para as despesas públicas de acordo com } \\
\text { a variação do IPCA. }\end{array}$ & $\begin{array}{l}\text { - Criação de emprego público que implique aumento de } \\
\text { despesa. } \\
\text { - Admissão ou contratação de pessoal, exceto para } \\
\text { reposição. } \\
\text { - Realização de concurso públicos. } \\
\text { - Ampliação ou incentivos de benefícios tributários. } \\
\text { - Celebração de contrato de repasse ou convênio com outros } \\
\text { entes federativos. }\end{array}$ \\
\hline
\end{tabular}

Fonte: Elaborado pelos autores.

A inovação apresentada pelo RRF em relação aos arranjos normativos de reestruturação dos desequilíbrios fiscais anteriores reside no fato de o novo marco regulatório (LC n. 159, 2017) trazer instrumentos e lógicas da lei de falência e da recuperação judicial de empresas para o setor público.

\section{OS RESULTADOS DO REGIME DE RECUPERAÇÃO FISCAL NO ESTADO DO RIO DE JANEIRO}

Nesta última seção, o objetivo é avaliar os impactos da implementação do RRF no estado do Rio de Janeiro, com o propósito de verificar se as medidas acordadas têm sido suficientes para reconduzir as finanças do estado ao reequilíbrio fiscal, ou seja, a um resultado primário capaz de estabilizar a dívida líquida.

A análise tem como ponto de partida a apresentação dos traços gerais do processo de adesão ao RRF pelo estado fluminense e, em seguida, uma avaliação dos três critérios adotados pelo RRF para certificar a gravidade fiscal-financeira dos estados. 
O estado do Rio de Janeiro apresentou seu Plano de Recuperação Fiscal em setembro de 2017, com vista ao enquadramento nos critérios estabelecidos pela LC n. 159 (2017). O "Plano de Recuperação Fiscal: 2017-2020", composto por 39 anexos, apresentava um conjunto de leis, o diagnóstico da situação fiscal-financeira e orçamentária do estado, diante da situação de desequilíbrio financeiro, e uma proposta detalhada das medidas de ajuste (obrigatórias e adicionais), com os impactos esperados e os prazos para a sua adoção (Conselho de Supervisão de Plano de Recuperação Fiscal do Estado do Rio de Janeiro, 2020).

As condições de elegibilidade do estado fluminense foram reconhecidas no pleno enquadramento ao conjunto dos três critérios de insustentabilidade fiscal-financeira (art. $3^{\circ}$ da LC 159, 2017) conforme detalhado anteriormente.

Em poucas semanas o acordo foi concluído com a União, sendo estabelecido o compromisso do estado com a execução de todas as medidas de caráter obrigatório e adicionais e com a observação dos condicionantes e vedações do termo de adesão, sob a ameaça de sanções pelo descumprimento das obrigações apontadas pelo Conselho de Supervisão do RRF5 .

Em contrapartida, a União concedia benefícios e facilidades fiscais ao estado fluminense, como o alongamento da dívida fundada estadual, a suspensão da cobrança de juros por 36 meses e dos requisitos legais exigidos na LRF para a contratação de operações de crédito e recebimento de transferências voluntárias pelo estado.

Nas palavras do então Secretário de Estado de Fazenda e Planejamento do Rio de Janeiro, Luiz Claudio Fernandes Lourenço Gomes, não havia alternativa para a recuperação da capacidade fiscal do estado senão a adesão ao RRF. Nesses termos, afirma de modo contundente que: "Sob o aspecto do estado como um todo não existe cenário alternativo ao RRF, ou o estado persevera com as medidas de controle da despesa e aumento da receita ou o resultado será indubitavelmente o retorno a uma crise financeira profunda”. (Secretaria de Estado de Fazenda e Planejamento do Estado do Rio de Janeiro, 2018, p. 10)

$\mathrm{Na}$ verdade, a adesão ao RRF não se constituiu num processo simples de negociação política. Alguns estados, diante da grave crise financeira e da impossibilidade de atenderem cumulativamente aos três critérios, optaram pela via da judicialização como uma "fuga para frente". O Rio de Janeiro foi o único estado que conseguiu adesão ao RRF desde sua criação.

Esse processo revelou uma situação esquizofrênica, considerando que o primeiro desafio era o enquadramento aos requisitos de habilitação no RRF, já que outros estados em condições fiscais igualmente dramáticas não conseguiram atender cumulativamente os três requisitos. Logo, era preciso empenhar-se para atender os três requisitos e conseguir os benefícios do acordo, uma vez que o estado já se encontrava em «estado de calamidade pública» na administração financeira. No segundo momento, o desafio era justamente o contrário, ou seja, o esforço era para alterar os indicadores que ensejaram a habilitação ao RRF e não mais se enquadrar nos três requisitos, o que demonstraria que o ajuste econômico estaria conduzindo as finanças do estado fluminense ao reequilíbrio.

Nesse contexto, a indagação fundamental que emerge é a seguinte: as medidas acordadas sob os princípios do RRF têm sido suficientes para reconduzir as finanças do estado ao reequilíbrio fiscal?

A resposta deve ser perscrutada por meio das variáveis que compõem os três critérios adotados pelo RRF. Para os fins aqui pretendidos, a opção metodológica é por uma avaliação de resultados globais e

\footnotetext{
${ }^{5}$ Conselho previsto na LC n. 159 (2017), formado por representantes do governo federal e do estado que aderiu ao RRF, responsável pelo acompanhamento das metas estabelecidas no plano de recuperação fiscal apresentado.
} 
não pelo monitoramento do efetivo cumprimento das medidas individuais do Plano de Recuperação Fiscal. Com efeito, minimizam-se os erros de estimativas de impactos das medidas, decorrentes de insuficiências, fragilidades ou inadequações de informações contábeis vis-à-vis as críticas apontadas nos relatórios de acompanhamento pelo Conselho de Supervisão do RRF. No entanto, possibilita verificar se o ajuste econômico foi suficiente para o reequilíbrio orçamentário-financeiro.

Com base nos dados disponibilizados pela Secretaria do Tesouro Nacional (2017b), além de informações publicadas pela Secretaria do Estado e Fazenda do Estado do Rio de Janeiro, por meio de seus Relatórios Resumidos de Execução Orçamentária (RREO) e Relatórios de Gestão Fiscal (RGF) (SEFAZ-RJ, 2019), é possível constatar que, dos três indicadores de avaliação das vulnerabilidades fiscais, apenas a relação entre despesas com pessoal e RCL recuou de 71,4\%, de setembro de 2017, para 48,9\%, no mesmo período do ano de 2019; ainda assim, com descumprimento de algumas vedações. Os demais indicadores ( 1 e 2) apresentaram uma trajetória crescente nos anos de 2017 a 2019 . O Gráfico 3 apresenta a evolução destes indicadores no período entre anos de 2008 a 2019.

\section{GRÁFICO 3 INDICADORES PARA ADESÃO AO REGIME DE RECUPERAÇÃO FISCAL ENTRE OS ANOS DE 2008 E 2019 DIVIDIDO POR QUADRIMESTRE*}

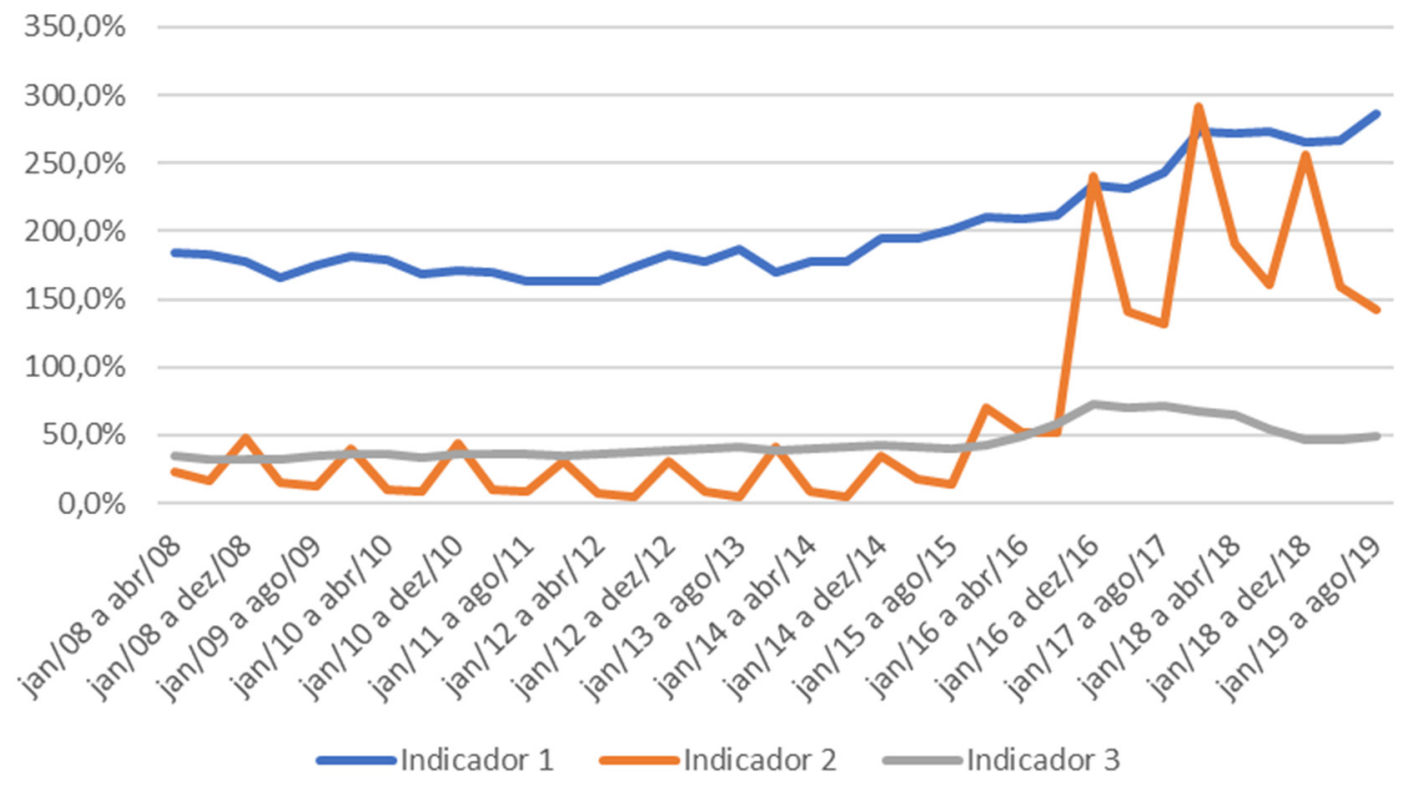

Indicador 1: razão percentual entre Dívida Consolidada Líquida (DCL) e RCL. Este indicador teve como objetivo aferir se a RCL anual era inferior à DCL, o que consistia em um dos critérios para a adesão ao RRF.

Indicador 2: razão percentual entre o total de obrigações contraídas e disponibilidades de caixa de recursos livres. Esse indicador teve como objetivo aferir se o ente tinha capacidade financeira para honrar suas dívidas de curto prazo.

Indicador 3: razão percentual entre o somatório das despesas de pessoal e relativas ao serviço da dívida, como numerador, e a RCL, como denominador. Esse indicador teve como objetivo verificar se o somatório de tais despesas alcançava percentuais maiores que $70 \%$ da RCL. Fonte: Elaborado pelos autores com base nos dados da Secretaria do Tesouro Nacional (2017b) e SEFAZ-RJ (2019).

Os resultados dos indicadores 1 e 2 apontam que o planejamento efetuado pelo estado do Rio de Janeiro, baseado nas obrigações e metas definidas no âmbito da adesão do RRF, não foi cumprido, isto é, o resultado financeiro acumulado em relação ao previsto foi abaixo do esperado. 
Dentre os diversos fatores que concorreram para explicar a grave crise financeira e o insucesso no processo de ajuste das finanças do estado fluminense, podem ser destacados: (i) a não retomada do crescimento econômico nacional; (ii) dificuldades políticas para a viabilização do acordo com a União; (iii) a situação do preço do barril do petróleo e, consequentemente, a arrecadação de royalties; (iv) a crise do setor petrolífero brasileiro em decorrência dos escândalos de corrupção da Petrobras; (v) dificuldade de incremento da RCL; (vi) má gestão da dívida fundada e da dívida de curto prazo do estado; (vii) descumprimento das vedações impostas pela LRF e o RRF.

É oportuno mencionar que todas as crises fiscais têm origem no aumento do hiato entre a necessidade de arrecadação e o caráter pró-cíclico das receitas e despesas públicas. Em um cenário de forte recessão econômica como o que atingiu o país a partir de 2014, torna-se iminente o estrangulamento fiscal-financeiro dos entes subnacionais, o que tende a revelar a ineficiência na gestão pública e a reverberar seus efeitos sobre a estabilidade social.

Nesse ínterim, a LC n. 159 (2017) estabeleceu a busca pela eficácia visando à ampliação e geração de receitas próprias; nesse caso, o incremento de receitas públicas foi um dos primeiros passos para garantir a solvência do ente subnacional.

Dessa maneira, um planejamento fiscal-financeiro foi apresentado em forma de anexo à Secretaria do Tesouro Nacional (2017c) e encaminhado para a formalização do acordo que pode ser dividido nos seguintes eixos: (i) modernização dos procedimentos de gestão fazendária; (ii) revisão do ICMS; (iii) venda da folha de pagamentos; (iv) venda de ativos mobiliários e imobiliários.

O Gráfico 4 demonstra que, a partir de 2018, a receita tributária do estado do Rio de Janeiro sofreu incrementos reais, quando comparada aos anos anteriores. Ao cotejar as informações dos meses de janeiro de 2017 com o mesmo período de 2018, houve um aumento da arrecadação, em termos reais, de 18,1\%. Esse crescimento é atribuído ao desempenho na arrecadação de ICMS, que cresceu aproximadamente $12 \%$ no período.

\section{GRÁFICO 4 EVOLUÇÃO MENSAL EM VALORES CONSTANTES DA RECEITA TRIBUTÁRIA DO ESTADO DO RIO DE JANEIRO ENTRE JANEIRO DE 2008 E SETEMBRO DE 2019 (EM BILHÕES DE REAIS R\$)}

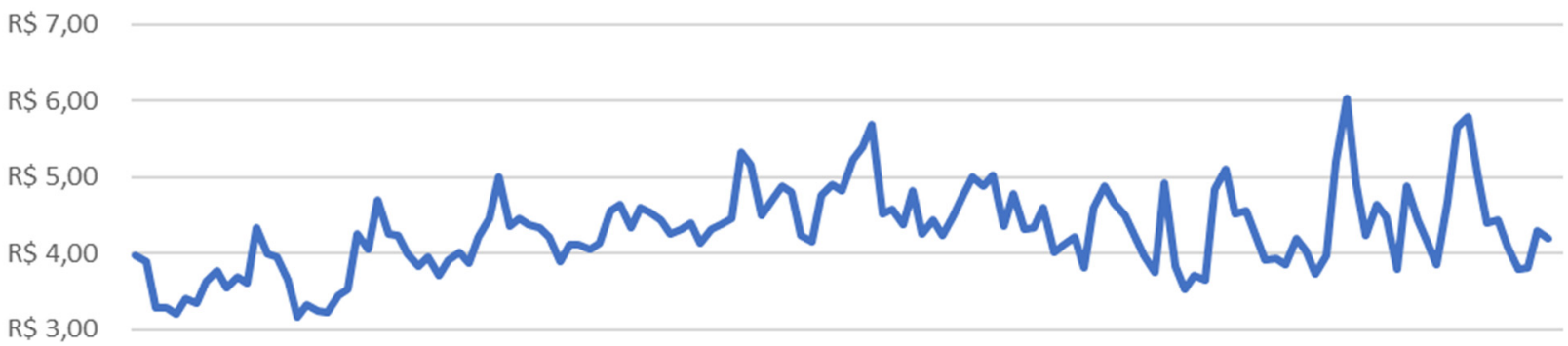

R\$ 2,00

$\mathrm{R} \$ 1,00$

$\mathrm{R} \$$ -

Fonte: Elaborado pelos autores com base nos dados da Secretaria do Tesouro Nacional (2017b) e SEFAZ-RJ (2019). 
Apesar do incremento de receitas tributárias ocorridas no biênio 2018-2019, a análise da série temporal dos últimos 10 anos indica que a arrecadação se encontra em um patamar inferior ao valor auferido nos anos de 2013 e 2014. Ademais, nas informações apresentadas no Anexo 17 do Plano de Recuperação Fiscal do Rio de Janeiro (2017), a expectativa era de um aumento na arrecadação de $45 \%$ no ano de 2018 e $80 \%$ em 2019 . Essa expectativa se mostrou totalmente frustrada e distante da realidade, tendo em vista que o crescimento das receitas em 2017 foi de apenas 1,15\% e, em 2018, de $8,8 \%$.

Outro elemento central estabelecido no acordo de adesão à LC n. 159 (2019) para geração de receitas foi a alienação de ativos públicos. Nos anexos apresentados pelo estado fluminense, constam as privatizações e a venda de patrimônio como elementos fundamentais para o reequilíbrio das contas do estado. A despeito de ter sido elemento central na adesão ao RRF e possuir autorização estadual (Lei Estadual nº 7.529/2017), a alienação das ações do capital social da Companhia Estadual de Águas e Esgotos do Estado do Rio de Janeiro (CEDAE) tornou-se bastante polêmica, o que resultou em diversas ações judiciais. As divergências se ampliaram com a promulgação da Lei Complementar Estadual $\mathrm{n}^{\circ} 182 / 18$, cujo artigo 22 revogava o artigo $1^{\circ}$, da Lei Estadual no 7.529/17 e, assim, desautorizava a alienação das ações representativas do capital social da CEDAE (Tribunal de Contas do Estado do Rio de Janeiro [TCE/RJ], 2019, p .135).

À vista disso, as receitas oriundas da alienação de bens, conforme atestam os dados apresentados no Gráfico 5, apresentaram resultados inferiores aos dos anos anteriores à assinatura do RRF e, portanto, abaixo do planejado.

\section{GRÁFICO 5 RECEITA EM VALORES CONSTANTES ORIUNDA DE ALIENAÇÃO DE BENS ENTRE 2008 E 2018 (EM BILHÕES DE R\$)}

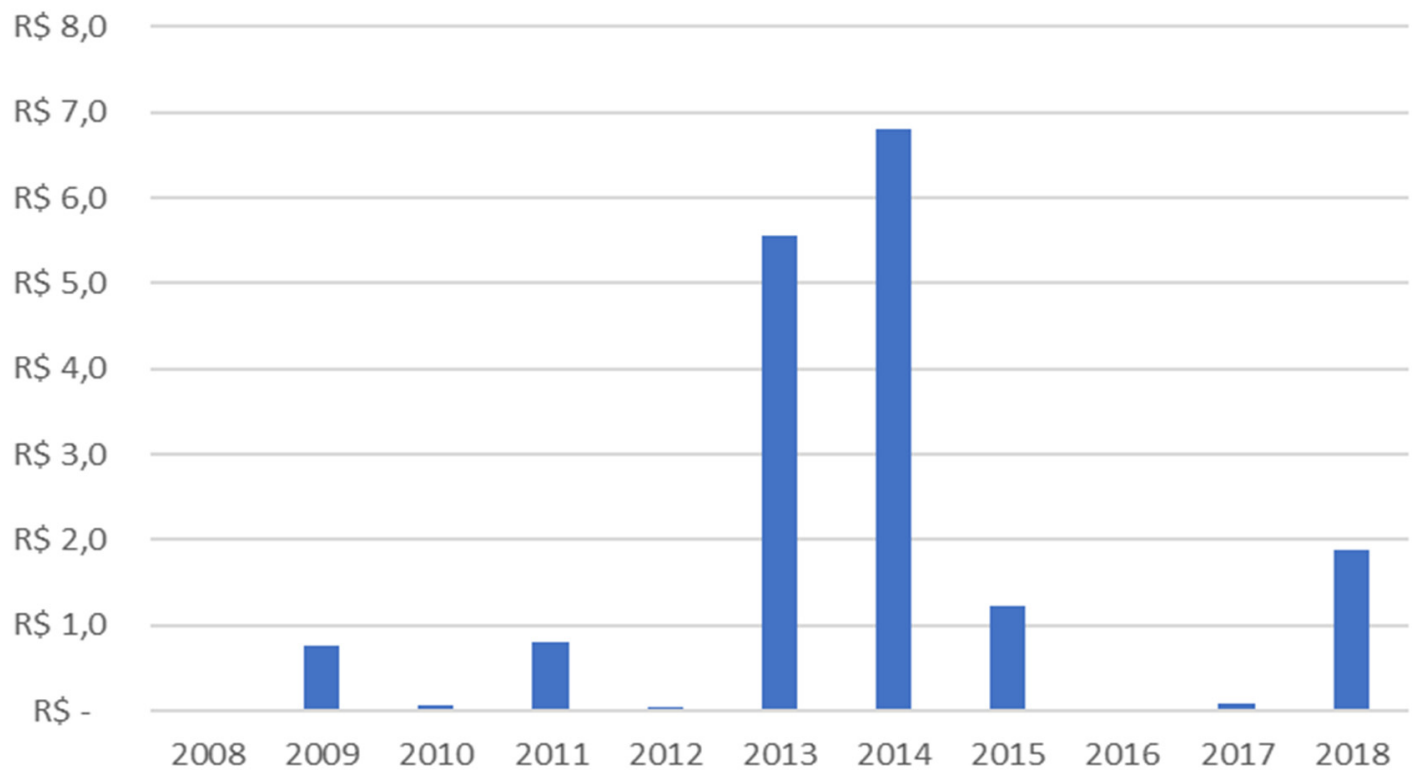

Fonte: Elaborado pelos autores com base nos dados da Secretaria do Tesouro Nacional (2017b) e SEFAZ-RJ (2019). 
Além disso, os documentos apresentados à Secretaria do Tesouro Nacional indicam que os descompassos fiscais-financeiros do estado fluminense têm sua gênese no descontrole das despesas correntes, em sua maioria gastos com pessoal. Porém, o artigo no 44 da LRF veda o uso de recursos oriundos da venda de ativos para o financiamento de despesas correntes, o que limita, em parte, o alcance do ajuste pretendido com a venda de patrimônio público.

Ainda assim, as receitas das alienações de ativos poderiam ser destinadas, por exemplo, para minimizar a insuficiência financeira do Regime Próprio de Previdência Social do estado do Rio de Janeiro ou ainda ser destinada para a redução do estoque da dívida do estado.

O resultado das medidas adotadas não foi satisfatório no cômputo geral. A RCL manteve-se em valores inferiores aos de 2014, apesar do acréscimo em relação aos anos de 2016 e 2017, oriundo do aumento da arrecadação do ICMS. O Gráfico 6 apresenta a evolução da RCL ao longo do período de 2008 a 2019.

\section{GRÁFICO 6 EVOLUÇÃO EM VALORES CONSTANTES DA RECEITA CORRENTE LÍQUIDA DO ESTADO DO RIO DE JANEIRO - 2008 A 2019 (EM BILHÕES DE R\$)}

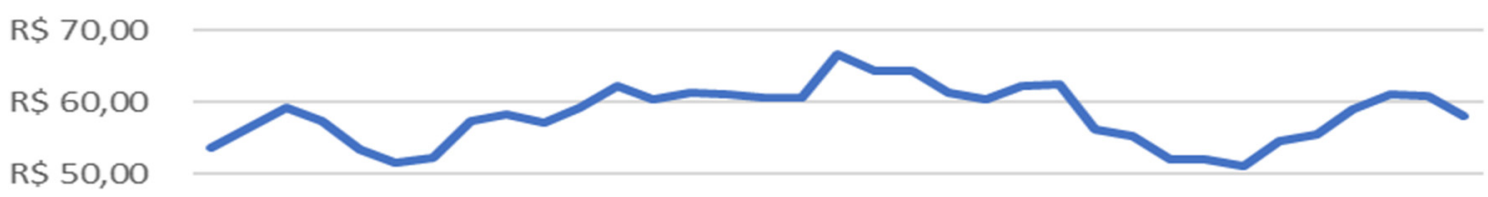

$\operatorname{RS} 40,00$

RS 30,00

RS 20,00

R\$ 10,00

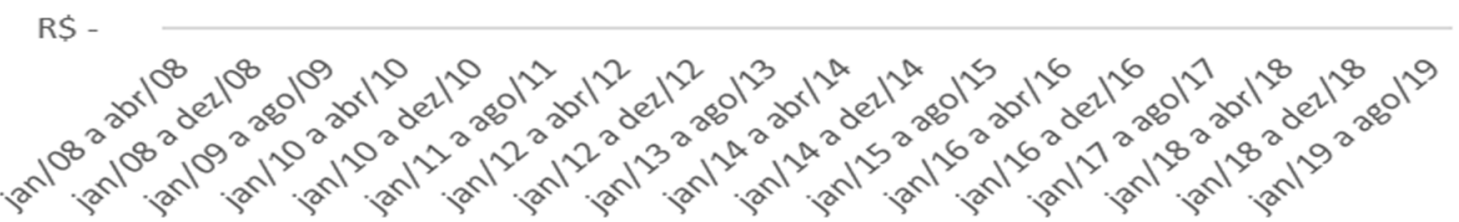

Fonte: Elaborado pelos autores com base nos dados da Secretaria do Tesouro Nacional (2017b) e SEFAZ-RJ (2019).

\subsection{0 endividamento estadual do Rio de Janeiro}

O segundo ponto de inflexão no ajuste fiscal promovido pelo RRF no estado do Rio de Janeiro está na gestão da dívida fundada e da dívida de curto prazo fluminense. O elemento basilar para a elaboração da Lei Complementar 159/2017 concentrava-se na tese de controle do endividamento que seriam responsáveis pelos desequilíbrios financeiros do setor público estadual.

A avaliação da evolução da dívida consolidada líquida (DCL) do estado é muito importante, uma vez que o equilíbrio proposto pelo RRF consiste na obtenção de resultados primários que permitam estabilizar a dívida líquida. Os dados expostos no Gráfico 7 apontam um aumento real de 86\% da 
DCL, no período entre 2008 e 2019, enquanto a RCL manteve-se com um crescimento abaixo de $8 \%$ no mesmo período. Após a adesão ao RRF o crescimento da DCL correspondeu a 31,7\%, o que é um indicativo de que o regime não logrou êxito em resolver um dos principais problemas fiscais do estado do Rio de Janeiro.

A trajetória ascendente do endividamento de longo prazo pode ser explicada pela expansão da dívida contratual, que aumentou 83\% no período correspondente entre 2008 e 2019. Cabe salientar que, deste crescimento, $80 \%$ estão vinculados a dívidas formalizadas com a União. O Gráfico 7 apresenta a trajetória da RCL e da DCL no estado do Rio de Janeiro, no período compreendido entre os anos de 2008 e 2011.

\section{GRÁFICO 7 EVOLUÇÃO EM VALORES CONSTANTES DA DÍVIDA CONSOLIDADA LÍQUIDA E RECEITA CORRENTE LÍQUIDA DO ESTADO DO RIO DE JANEIRO - 2008 A 2019 (EM BILHÕES DE R\$)}

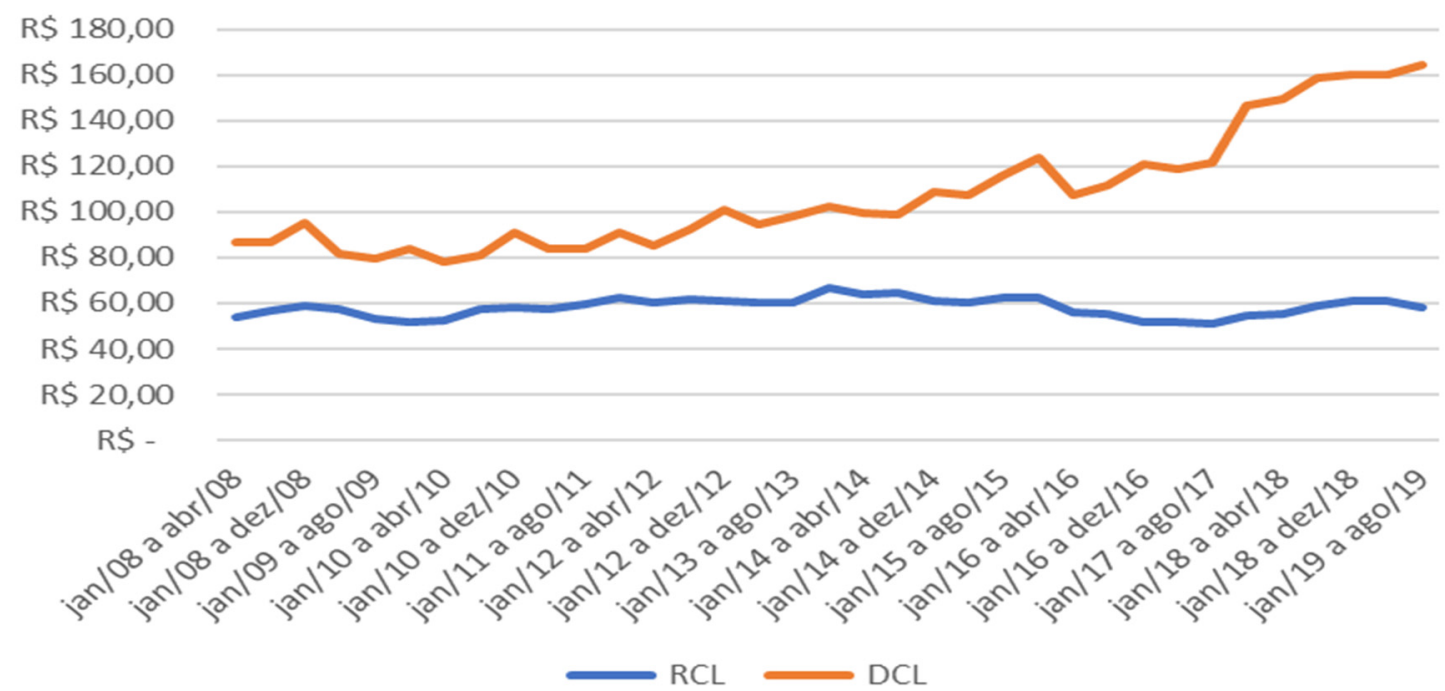

Fonte: Elaborado pelos autores com base nos dados da Secretaria do Tesouro Nacional (2017b) e SEFAZ-RJ (2019).

A análise do endividamento de curto prazo do estado do Rio de Janeiro revela uma divergência com o discurso de ajuste fiscal das autoridades governamentais, sobretudo levando-se em conta os restos a pagar processados. Convém frisar, por oportuno, que nos termos do acordo havia a previsão de inscrição de valor "zero" a partir da adesão ao RRF (TCE/RJ, 2019, p. 130). No entanto, em 2018, o estado do Rio de Janeiro deixou R $\$ 18$ bilhões em restos a pagar não quitados em 2019. Esse montante correspondia a aproximadamente $22 \%$ do orçamento total do estado fluminense.

Assim, mesmo após assinar os compromissos expressos no termo de adesão ao RRF, o estado continua a se endividar e não consegue cumprir com seus compromissos de curto prazo. No período de 2017 a 2018, os restos a pagar do estado cresceram aproximadamente 42\%, e no ano de 2019 mantiveram trajetória ascendente. A disponibilidade bruta em caixa para honrar esses compromissos tem apresentado crescimento, porém ainda em montante insuficiente para honrar os compromissos de curto prazo, conforme exemplifica o Gráfico 8. 
Tem-se evidente, nesses aludidos termos, que o aumento dos restos a pagar sem disponibilidade de recursos financeiros em caixa resulta em dificuldades crescentes para a extinção das obrigações. Com efeito, pode ocorrer uma rápida deterioração na oferta de bens e serviços públicos, ao passo que a ausência de pagamento de fornecedores torna-se objeto de suspensão de contratos.

\section{GRÁFICO 8 EVOLUÇÃO EM VALORES CONSTANTES DOS RESTOS A PAGAR E DISPONIBILIDADE EM CAIXA ENTRE OS ANOS DE 2008 E 2019 (EM BILHÕES DE R\$)}

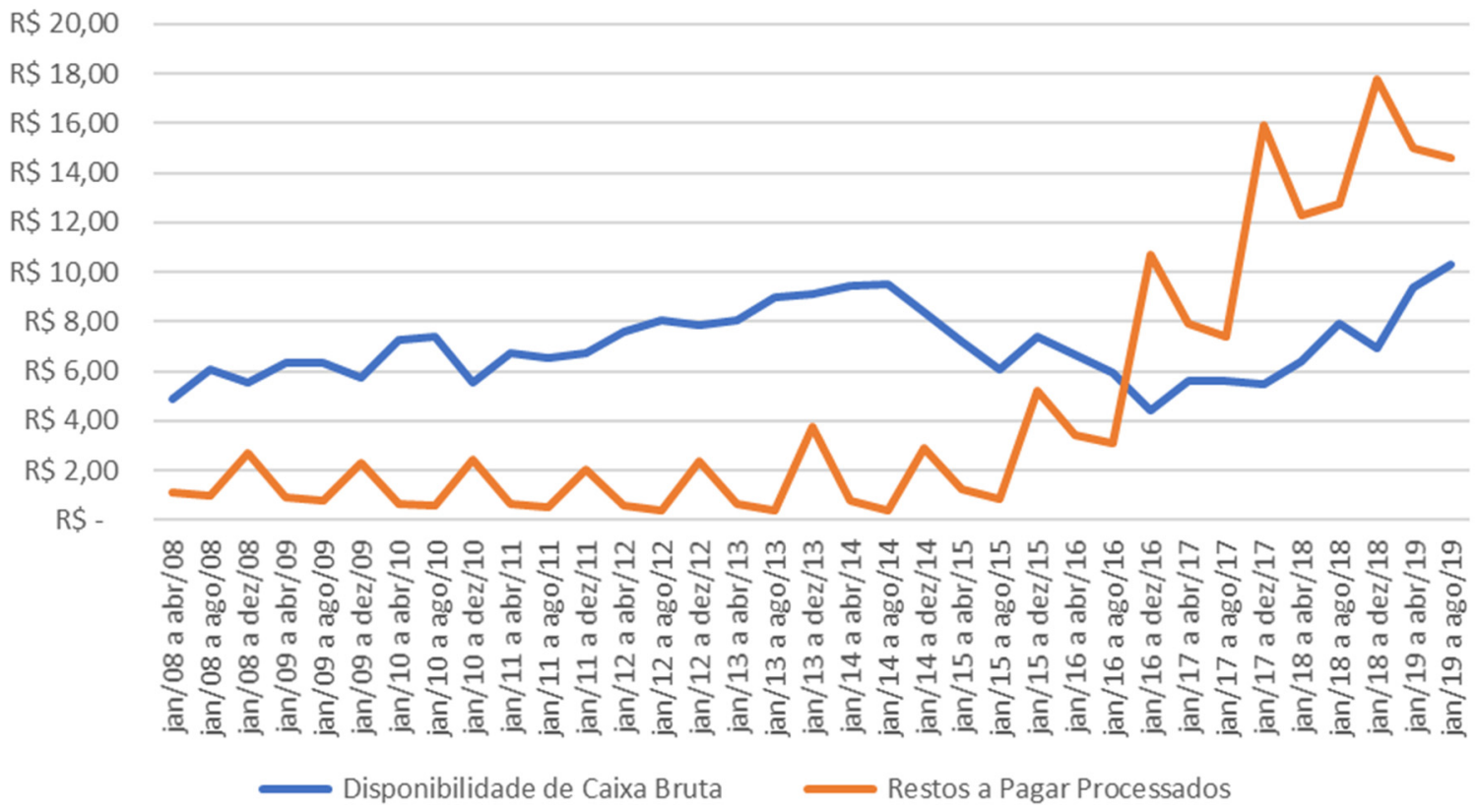

Fonte: Elaborado pelos autores com base nos dados da Secretaria do Tesouro Nacional (2017b) e SEFAZ-RJ (2019).

\section{CONCLUSÃo}

A recente crise econômica e fiscal novamente atingiu as bases da federação brasileira. A constrição financeira dos governos subnacionais evidenciou-se em atrasos no pagamento de salários de servidores públicos, na falta de investimentos em áreas estratégicas, como saúde, educação e segurança pública, na precarização da oferta de diversos serviços públicos, em obras atrasadas, pagamentos postergados a fornecedores, aumento do endividamento público e entraves nas relações federativas.

Diante dos desequilíbrios das contas públicas e do elevado endividamento dos estados brasileiros, a alternativa apresentada, num primeiro momento, foi a LC n. 156 (2016), com o objetivo de promover o reequilíbrio fiscal. Posteriormente, um novo plano de auxílio aos estados foi apresentado com a aprovação da LC n. 159 (2017), o RRF.

Em virtude da rigidez dos critérios para a habilitação ao RRF, apenas o estado do Rio de Janeiro logrou êxito na proposta de adesão, a despeito de mais da metade dos estados da federação estar em estado de calamidade financeira. Isso demonstra uma relação federativa cada vez mais afastada dos 
preceitos constitucionais do federalismo cooperativo e de uma solução articulada e harmônica entre a União e os entes subnacionais.

A análise das finanças do estado fluminense, após mais de dois anos da adesão ao RRF, mostrou que as medidas adotadas não foram suficientes para a retomada de uma trajetória sustentável de reequilíbrio das contas públicas, ou seja, não conduziu a um resultado primário capaz de estabilizar a dívida líquida.

A despeito de não ter atingido até o momento o reequilíbrio financeiro do estado, sendo esta sua principal meta, não se pode qualificar o regime como fracassado, pois, ainda assim, o Rio de Janeiro foi extremamente beneficiado. Impõe-se reconhecer que, numa situação de não adesão ao RRF, teria ocorrido iminentemente uma tragédia social sem precedentes no estado fluminense. Ademais, nos dois primeiros anos de vigência do RRF, o estado deixou de pagar $\mathrm{R} \$ 34,1$ bilhões em dívidas, sendo $\mathrm{R} \$ 22,8$ bilhões referentes a dívidas com a União e $\mathrm{R} \$ 11,2$ bilhões de empréstimos com garantias do Tesouro Nacional, além da possibilidade de contratar novas operações de crédito.

Quanto à alegação do Governo do Rio de Janeiro de que as metas acordadas não estão sendo cumpridas por serem inexequíveis, draconianas, é importante não perder de vista que o Plano de Recuperação Fiscal foi preparado pelo próprio estado fluminense. Além disso, o governo, em meio a uma crise estrutural do estado, optou por firmar acordos sem pactuar politicamente com a sociedade. Não obstante, impôs o peso do ajuste às camadas da população mais vulneráveis, que não possuem condições financeiras de acesso aos serviços privados.

A persistência de uma situação fiscal crítica mostra que pouco se progrediu no caminho do equilíbrio das finanças públicas do estado. A avaliação da efetividade das medidas acordadas no plano, por meio da análise dos indicadores que qualificam a gravidade da crise fiscal, sobretudo no período pós-adesão ao RRF, revela que não houve mudanças significativas em direção à sustentabilidade fiscal do estado fluminense.

Diante do exposto neste estudo, espera-se ter demonstrado que as condições de insolvência das finanças dos estados têm constrangido as relações federativas e promovido a ascensão de uma espécie de federalismo sem pactuação. A repercussão desse processo impõe a necessidade de discussão de um novo pacto federativo, mais harmônico e cooperativo, uma vez que os resultados dos ajustes fiscais em curso têm sido socialmente dramáticos, com o retorno de milhares de brasileiros à situação de extrema pobreza. De todo modo, um olhar crítico sobre as negociações da dívida dos estados e do equilíbrio das finanças estaduais revela um futuro que espelha o passado e realça o sentimento de um déjà $v u$ federativo. 


\section{REFERÊNCIAS}

Abrúcio, F. L. (1998). Os barões da Federação: os governadores e a redemocratização brasileira. São Paulo, SP: DCP/USP/Hucitec.

Abrúcio, F. L. (2005). Reforma do Estado no federalismo brasileiro: a situação das administrações públicas estaduais. Revista de Administração Pública, 39(2), 401-419.

Abrúcio, F. L. (2007). Trajetória recente da gestão pública brasileira: um balanço crítico e a renovação da agenda de reformas. Revista de Administração Pública, 1(spe), 67-87.

Ahmad, E., Albino-War, M., \& Singh, R. (2006). Subnational public financial management: institutions and macroeconomic considerations. In E. Ahmad, \& G. Brosio (Eds.), Handbook of Fiscal Federalism. Chelthenham, UK: Edward Elgar Publishing Limited.

Aquino, A. C. B., \& Azevedo, A. R. R. (2017). Restos a pagar e a perda da credibilidade orçamentária. Revista de Administração Pública, 51(4), 580-595. Recuperado de https://dx.doi.org/10.1590/00347612163584

Caldeira, A., Wilbert, M., Moreira, T., \& Serrano, A. (2016). Sustentabilidade da dívida estadual brasileira: uma análise da relação dívida líquida e resultado primário. Revista de Administração Pública, 50(2), 285-306. Recuperado de http:// bibliotecadigital.fgv.br/ojs/index.php/rap/article/ view/60863/59081

Cheema, G. S., \& Rondinelli, D. A. (1983). Decentralization and development: policy implementation in developing countries. London, UK: Sage Publications.

Conselho de Supervisão de Plano de Recuperação Fiscal do Estado do Rio de Janeiro. (2020). Plano de Recuperação Fiscal do Estado do Rio de Janeiro (2017-2020). Recuperado de https://www2. camara.leg.br/atividade-legislativa/comissoes/ comissoes-temporarias/externas/55a-legislatura/ intervencao-na-seguranca-publica-do-riode-janeiro/documentos/audiencias-publicas/ ApresentaoConselhodeSupervisodoRegimede RecuperaoFiscal030418.pdf

Decreto no 9.109, DE 27 de julho de 2017. (2017). Regulamenta a Lei Complementar no 159 , de 19 de maio de 2017, que institui o Regime de Recuperação Fiscal dos Estados e do Distrito Federal. Brasília, DF.

Estado de Santa Catarina. (2016). Mandado de Segurança n. ${ }^{\circ}$ 34.023/SC: Questiona a forma de capitalização da dívida dos Estados para com a União. Relator Min. Edson Fachin. Brasília, DF: Supremo Tribunal Federal.

Faguet, J. P. (1997, December). Decentralization and local government performance. Technical Consultation on Decentralization. Rome, Italy: Food and Agriculture Organization.

Faguet, J. P. (2004). Does decentralization increase government responsiveness to local needs? Evidence from Bolivia. Journal of public economics, 88(3-4), 867-893.

Hamilton, A. (1767). The Federalist Papers. Recuperado de https://www.congress.gov/resources/ display/content/The+Federalist+Papers

Instituto Fiscal Independente. (2017). A crise fiscal dos estados e o novo acordo com a União (Relatório de Acompanhamento Fiscal). Recuperado de https://www12.senado.leg.br/ifi/relatorio-deacompanhamento-fiscal

Lei Complementar $n^{\circ}$ 101, de 04 de maio de 2000. (2000). Lei de Responsabilidade Fiscal. Brasília.A crise fiscal dos estados e o novo acordo com a União. Relatório de Acompanhamento Fiscal. Recuperado de https://www12.senado.leg.br/ifi/relatorio-deacompanhamento-fiscal

Lei Complementar no 148, de 25 de novembro de 2014. (2014). Altera A Lei Complementar no 101, de 4 de maio de 2000, que Estabelece Normas de Finanças Públicas Voltadas para a Responsabilidade na Gestão Fiscal; Dispõe sobre Critérios de Indexação dos Contratos de Refinanciamento da Dívida Celebrados entre a União, Estados, o Distrito Federal e Municípios; e dá outras Providências. Brasília, DF.

Lei Complementar n. ${ }^{\circ}$ 156, 28 de dezembro de 2016. (2016). Estabelece o Plano de Auxílio aos Estados e ao Distrito Federal e medidas de estímulo ao reequilíbrio fiscal; e altera a Lei Complementar no 148, de 25 de novembro de 2014, a Lei no 9.496, de 11 de setembro de 1997, a Medida Provisória no 2.192-70, de 24 de agosto de 2001, a Lei no 8.727, de 5 de novembro de 1993, e a Lei Complementar no 101, de 4 de maio de 2000. Brasília, DF. 
Lei Complementar $n^{\circ}$ 159, de 19 de maio de 2017. (2017). Institui o Regime de Recuperação Fiscal dos Estados e do Distrito Federal e Altera as Leis Complementares $\mathrm{n}^{\circ} 101$, de 4 de maio de 2000, e ${ }^{\circ} 156$, de 28 de dezembro de 2016. Brasília, DF. Recuperado de http://www.planalto.gov.br/ ccivil_03/leis/LCP/Lcp159.htm

Lei $n^{\circ} 182$ de 20 de setembro de 2018. (2018). Dispõe sobre a redução de multa e de juros de mora, no caso de pagamentos em parcela única ou mais de uma parcela, de créditos tributários relativos ao icms, na forma que especifica, de acordo com o autorizado no convênio ICMS 75/18. Rio de Janeiro, RJ.

Lei no 7529 de 07 de março de 2017. (2017). Autoriza O Poder Executivo A Alienar Ações Representativas Do Capital Social Da Companhia Estadual De Águas E Esgotos - Cedae e dá Outras Providências. Rio de Janeiro, RJ.

Lei no 13.254, de 13 de janeiro de 2016. (2016). Dispõe sobre o Regime Especial de Regularização Cambial e Tributária (RERCT) de recursos, bens ou direitos de origem lícita, não declarados ou declarados incorretamente, remetidos, mantidos no exterior ou repatriados por residentes ou domiciliados no País. Brasília, DF.

Ligthart, J. E., \& van Oudheusden, P. (2015). In government we trust: the role of fiscal decentralization. European Journal of Political Economy, 37, 116-128.

Luc, E., \& Badia, M. (2013). Too Small to Fail? Subnational Spending Pressures in Europe (IMF Working Paper n. 13/46).

Melo, M. A. (1996). Crise federativa, guerra fiscal e "hobbesianismo municipal": efeitos perversos da descentralização? São Paulo em perspectiva, 10(1), 11-20.

Mora, M. (2016). Evolução Recente da Dívida Estadual. Brasília, DF: IPEA.

Musgrave, R. A. (1960). The Theory of Public Finance: a study in Public Economy. The Journal of Finance, 15(1), 118-120.

Oates, W. E. (1972). Fiscal federalism. San Diego, CA: Harcourt Brace Jovanovich Press.

Paiva, C. C., Torrezan, R. G. A., \& Paiva, S. C. F. (2016). Descentralização fiscal e gastos locais em Gestão Ambiental: um estudo exploratório para os municípios paulistas. Contabilidade, Gestão e Governança, 19(3), 465-484.

Projeto de Lei n⿳3 343 de 23 de fevereiro de 2017. (2017). Institui o Regime de Recuperação Fiscal dos Estados e do Distrito Federal e dá outras providências. Brasília, DF.

Prud'Homme, R. (1995). The dangers of decentralization. The world bank research observer, 10(2), 201-220.

Rodden, J. A., Eskeland, G. S., \& Litvack, J. (2003). Introduction and Overview. In J. A. Rodden, G.S. Eskeland, \& Litvack, J. (Eds.), Fiscal decentralization and the challenge of hard budget constraints. Cambridge, MA: The MIT Press.

Secretaria da Fazenda do Rio de Janeiro. (2019). Relatórios Fiscais. Recuperado de http://www. fazenda.rj.gov.br/sefaz/

Secretaria de Estado de Fazenda e Planejamento do Estado do Rio de Janeiro. (2018). Balanço e Recomendações. SEFAZ. Balanço das Principais Ações (2015-2018) e Recomendações para a Próxima Gestão (2019-2022): contribuições para o Planejamento Estratégico da SEFAZ. Rio de Janeiro, RJ: SEFAZ. Recuperado de http://www. fazenda.rj.gov.br/sefaz/ShowProperty?nodeId $=\% 2$ FUCMServer\%2FWCC337608\%2F\%2FidcPrimary File\&revision=latestreleased

Secretaria do Tesouro Nacional. (2017a). Boletim de Finanças dos Entes Subnacionais. Brasília, DF: Autor. Recuperado de https://www.tesouro.fazenda. gov.br/documents/10180/318974/Boletim+de+ Finanças+dos+Entes+Subnacionais +28-8-2017/ c92cd1c4-b930-4517-a57a-79543fa0ace6

Secretaria do Tesouro Nacional. (2017b). SiconfiVersão: 2.0. Recuperado de https://siconfi.tesouro. gov.br/siconfi/index.jsf\#

Secretaria do Tesouro Nacional. (2017c). Plano de Recuperação Fiscal do Estado do Rio de Janeiro. Recuperado de https://www.tesourotransparente. gov.br/publicacoes/plano-de-recuperacao-fiscal-doestado-do-rio-de-janeiro/2019/30

Shah, A. (2000, enero). Federalismo fiscal y governabilidade macroeconómica: en lo próspero y en lo adverso? Trimestre Fiscal. INDETEC, 69(21).

Ter-Minassian, T. (1997). Fiscal Federalism in Theory and Practice. Washington, DC: International Monetary Fund. 
Ter-Minassian, T. (1999). Decentralization and macroeconomic management. In K. Fukusaku, \& L. R. Mello Jr. (Ed.), Fiscal decentralization in emerging economies: Governance Issues (pp. 55-65). Paris, France: OECD.

Ter-Minassian, T. \& Craig, J. (1997). Control of Subnational Government Borrowing. In T. Ter-
Minassian (Ed.), Fiscal Federalism in Theory and Practice (Chapter 7). Washington, DC: IMF.

Tiebout, C. (1956). A pure theory of local government expenditures. Journal of Political Economy, 64, 416-424.

Tribunal de Contas do Estado do Rio de Janeiro. (2019). Contas de Governo Estado do Rio de Janeiro 2018, (Vol. 1, 878 p.). Rio de Janeiro RJ.

\section{Raphael Guilherme Araujo Torrezan}

https://orcid.org/0000-0002-4690-406X

Doutorando em Economia pela Faculdade de Ciências e Letras de Araraquara (FCLAr) na Universidade Estadual Paulista "Júlio de Mesquita Filho" (UNESP). E-mail: raphael.torrezan@unesp.br

\section{Cláudio César de Paiva}

https://orcid.org/0000-0001-7837-8706

Professor Associado do Departamento de Economia da Faculdade de Ciências e Letras de Araraquara (FCLAr) na Universidade Estadual Paulista "Júlio de Mesquita Filho" (UNESP). E-mail: claudio.paiva@unesp.br 